\title{
SOCIO - DEMOGRAPHIC PROFILE OF PSYCHOACTIVE SUBSTANCE USERS IN POKHARA VALLEY
}

\author{
Upadhayaya K. D. ${ }^{1}$
}

\section{ABSTRACT:}

The socio-demographic profile of psychoactive substance users (excluding alcohol) attending neuropsychiatric out patient department of western regional hospital Pokhara during the period Feb. 1997 to Oct. 1998 was studied. All the 55 cases were males, more than $50 \%$ started drug use before the age of $24,80 \%$ of users were from urban areas, buprenorphine intravenous injection was the commonest drug of abuse $\mathbf{( 4 1 . 8 \% )}$ ) followed by cannabis $(\mathbf{3 0 . 9} \%)$, heroin $(\mathbf{1 1 \%})$. The implications of the findings with an emphasis on future direction are discussed.

The phenomenon of drug use in Nepal is not new but the changing trends in use is much more dangerous than in the past. Cannabis use which was limited to traditional and ceremonial use on certain occasions like in Shivaratri or phagupurnima, or smoked by Sadhus, is now increasingly abused by the youth of the urban areas. Hard drugs like heroin use was the major concern a few years ago, but now the drugs like buprenorphine intravenous and nitrazepam and nitrazepam tablets are also abused and they are likely to be the major drugs of abuse.

\section{MATERIAL AND METHODS:}

Pokhara is the regional head quarter of the western region and the most popular tourist destination in Nepal. The sub-metropolitan city has a population of about 110,000. The city has a 200 bedded general hospital where psychiatric services are available in addition to other specialties. The study includes all patients coming to neuropsychiatric OPD of Western Regional Hospital with current psychoactive substance use problems (excluding alcohol), for the consultation and treatment. Clients were interviewed by consultant psychiatrist and a questionnaire prepared for the drug screening purpose was filled.

\section{RESULTS:}

A total of 55 cases were seen during the study period. The nature and type of drug abuse, including demographic data of 55 cases who came between Feb. 1997 to Oct. 1998 are presented.

\section{Age profile of drug users.}

Table 1

\begin{tabular}{c|c|c|c|}
\hline$<15$ yr. & $15-24$ yr. & $25-34$ yr. & $>35$ yr. \\
\hline $2(4 \%)$ & $26(47 \%)$ & $19(35 \%)$ & $8(15 \%)$ \\
\hline
\end{tabular}

1. Senior Consultant Psychiatrist, Western Regional Hospital Pokhara, Nepal.

Paper presented in the First National Conference of Psychiatrist, Association of Nepal, held in B.P. Koirala Institute of Health Sciences, Dharan from 13-14 November 1998. 
Majority of drug users (86\%) were adolescents or adults. Two clients started drug use before the age of 15 , one of the them was $13 \mathrm{yr}$. and other was $14 \mathrm{yr}$. of age when they started drugs. Both of them smoked marihuana as the first drug with their friend's influence in the school along with their several friends.

\section{SEX DISTRIBUTION:}

All were males, which shows that drug related consultations are mainly a male phenomenon.

\section{MARITAL STATUS:}

29 clients $(53.7 \%)$ were unmarried and $25(46.3 \%)$ clients were married. However these data do not clearly reflect marital status and drug use, as many clients started drug use when they were not married.

\section{OCCUPATIONAL STATUS:}

\section{Table 2}

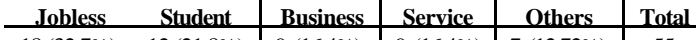
\begin{tabular}{|cc|c|c|c|c}
\hline $18(32.7 \%)$ & $12(21.8 \%)$ & $9(16.4 \%)$ & $9(16.4 \%)$ & $7(12.72 \%)$ & 55
\end{tabular}

Unemployed people and students unable to do well in studies, used drugs more frequently that the people who were employed or had their own business (table 2)

\section{EDUCATIONAL STATUS:}

\section{Table 3}

\begin{tabular}{ll|ll} 
A few classes Test pass & SLC Certificate Higher education
\end{tabular} \begin{tabular}{ll|lll}
$16(29 \%)$ & $11(20 \%)$ & $19(35 \%)$ & $8(15 \%)$ & $1(2 \%)$ \\
\hline
\end{tabular}

Almost all of them had studied in school but majority of them had not done well, only a few were the students of college and only one client had higher education. It shows that better the educational status, lesser the drug use problems.

\section{RURAL - URBAN STATUS:}

There were 44 clients from urban area and 11 from villages. Although a fifth of the clients were rural, they were from the neighboring villages and most of the drug users were from Pokhara sub-metropolitan. It shows that drug abuse is mainly a problem of cities but villages are also not untouched.

\section{RELIGION:}

$31(67.4 \%)$ of clients were Hindus and 15 (32.6\%) clients were Buddhist

\section{ETHNIC GROUP:}

\section{Table 4}

\begin{tabular}{l|ll|l|ll} 
Gurung & Chhetri & Brahmin & Newar & Pariyar etc & Others
\end{tabular}

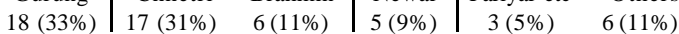

Drug use problem was seen in Gurungs, Chhetris, Brahmins and Newars. In the group others ethnic groups included in the study were Magars, Kumals, Lamas, and Tibetians.

\section{DURATION OF DRUG USE IN YEARS:}

Table 5

\begin{tabular}{ccc|cc}
\hline$<1 \mathrm{yr}$. & $1-2 \mathrm{yr}$. & $3-4 \mathrm{yr}$. & $5-6 \mathrm{yr}$. & $>6 \mathrm{yr}$. \\
$12(22 \%)$ & $15(27 \%)$ & $7(13 \%)$ & $8(15 \%)$ & $13(24 \%)$ \\
\hline
\end{tabular}

As seen in the table 5 , about $50 \%$ of drug users came for consultation within 2 years of their drug use. This shows that drug addicts want help to get rid of their drug problems.

CHOICE OF PRIMARY DRUG OF ABUSE:

\section{Table 6}

\begin{tabular}{ccc|c|c|} 
Buprenorphine & Cannabis & Heroin & $\begin{array}{c}\text { Codeine }+ \\
\text { Antihistamines } \\
+ \text { pain killers } \\
5(9.1 \%)\end{array}$ & Nitrazepam \\
\hline $23(41.8 \%)$ & $17(30.9 \%)$ & $6(11.00 \%)$ & $4.3 \%)$ \\
\hline
\end{tabular}

A few years ago, heroin (brown sugar) was more commonly used but now the drug use pattern is changing and use of buprenorphine intravenous is increasing. One of the reasons given by the users was non-availability of heroin for substituting buprenorphine which is said to be easily available in the local market. There were only 6 clients in this sample who used heroin. Two of them used 
white sugar and others brown sugar. This shows that if drugs which have abuse potentials are readily available in the market, they are abused. If one misused drug is not easily available, new drug of similar nature is tried by the drug users. Codeine containing cough syrup, buprenorphine injection, nitrazepam tablets and ephedrine, codeine and promethazine tablets are some of the example of changing trend in drug use when main drug like heroin is not easily available.

One client used codeine tablets only. He used to take codeine containing cough syrup; when it was not available he started taking 10 to 20 tablets of codeine $(1 \mathrm{tab} .=15 \mathrm{mg}$.) daily. Other two clients were using what they called "formula drug", one of them was using codeine 5 tablets + ephedrine 2 tablets + pheniramin maleate 2 tablets (taken together as one does 2-3 times daily, each tablet of ephedrine contained $15 \mathrm{mg}$. and that of pheniramin $7.5 \mathrm{mg}$.). One other client used different combination: codeine 4 tablets + promethazine $(25 \mathrm{mg}$. each) 3 tablets + ephedrine 3 tablets as one dose and such doses two to three times daily. The commonest benzodiazepine of abuse was nitrazepam and the usual dose used was 40 to $50 \mathrm{mg}$. dialy.

\section{METHOD OF TAKING PRIMARY DRUG OF ABUSE:}

\section{Table 7}

\begin{tabular}{|ccc|c|}
\hline Intravenous & Smoking & Chasing & Oral \\
\hline $24(44 \%)$ & $17(31 \%)$ & $5(9 \%)$ & $7(16 \%)$ \\
\hline
\end{tabular}

As seen in table 7 , intravenous drug use was the most common method followed by smoking, oral use and chasing. All the buprenorphine users injected drug the several times daily, dose range was 4 to 15 ampoules per day. None of the buprenorphine users were using sublingual buprenorphine. Cannabis users smoked in the form of cigarettes and codeine, nitrazepam and analgesic users took orally and heroin users mostly chased drug except one who was injecting it. It is worth noting that most of the buprenorphine users were past heroin users and they were chasing heroine before starting buprenorphine use.

Cannabis was mostly smoked mixed with tobacco in the form of cigarettes, several times daily. Only one case mixed cannabis with food and took it orally. Cannabis use in Shivaratri and Phagupurnima was a common phenomenon. Often the people gathered in the local Shiva temple and smoked cannabis in groups with the intention of entertainment. No cost was involved in the villages, in the cities a packet for a day would not cost more than rupees 10 , which is cheaper than good quality cigarettes. The intravenous users have shared needle initially at least with one or two of their friends. However most of them were aware of the risk of sharing needles and had stopped, but they did use the same syringe many times after cleaning with boiled water. In this study group, only one case was hepatitis B positive.

One client injected brown sugar intravenously. The method of injecting as described by the client was "mix a dose of brown sugar (100 to $150 \mathrm{mg}$.) with half tablet of vit.C (250 mg.) dissolve in water, boil it in a spoon and filter it with the help of a cotton ball i.e. soak the cotton ball in the boiled fluid and draw it into syringe by putting its needle tip to the soaked cotton ball and inject". He had been doing it for more than a year.

\section{SECONDARY DRUG OF ABUSE:}

Abuse of benzodiazepines and other drugs is a well known phenomenon in heroin addicts. Most of the heroin users started using buprenorphine as a substitute to heroin. In the present sample, 20 clients were not using any secondary drug where as 35 clients used various other drugs depending upon the availability of primary or the secondary drugs. 
Opioid addicts were using other drugs, most commonly nitrazepam tablets. When primary drug of abuse was not available, they used secondary drugs to avoid the withdrawal symptoms and later continued to use them in addition to their main drugs. The opioid addicts often used secondary drugs to enhance the effect of primary drug. Most common secondary drugs of abuse were Cannabinoids (ganja \& charas), codeine and nitrazepam. Other drugs of abuse were: actifed tablets, spasmindon tablets, opium, spasmo-proxyvon, codeine containing cough syrup, codeine tablets, magic mushroom, diazepam and alcohol. 14 (40\%) of the hard drug users were using secondary drug on the regular basis and others were using occasionally only.

As regards benzodiazepines use, most common was nitrazepam 30 to $40 \mathrm{mg}$. daily. Regular nitrazepam users said they "feel fresh, active and have ability to discuss and courage to fight". Drug users tried diazepam in place of nitrazepam but it did not give them the desired effects. In this study, clients with cannabis as the primary drug of abuse were not using other drugs but almost all the clients with opioids as the primary drug of abuse were using secondary drugs.

\section{AGE OF INITIATION OF DRUG USE:}

\section{Table 8}

\begin{tabular}{|cc|c|c|}
\hline$<16$ yr. & $16-20$ yr. & $21-25$ yr. & $>25$ yr. \\
\hline $5(9 \%)$ & $23(42 \%)$ & $17(31 \%)$ & $10(18 \%)$ \\
\hline
\end{tabular}

As seen in the table over $90 \%$ of the users in this sample started drug use before the age of 25 and more than $50 \%$ started before they were 20 .

\section{DIAGNOSIS:}

Opioid dependence

Benzodiazepines

Cannabis abuse

$\begin{array}{ll}34 & 62 \% \\ 4 & 7 \% \\ 17 & 31 \%\end{array}$

The figure shown above for Benzodiazepine dependence is for its primary use and excludes all other clients who used it as a secondary drug.

\section{CO-MORBID PSYCHIATRIC DISORDER:}

No psychiatric disorder was found in 28 clients. Anxiety neurosis was the commonest disorder associated with drug abuse. Of the total 8 such cases, 5 had features of panic anxiety and 3 had generalized anxiety disorder. Marital discord, adjustment problems in the family, bipolar affective disorder and personality disorder were found in a small percentage of cases. Whether marital discord and family problems were the cause of drug use or the effects was difficult to assess.

\section{ASSOCIATED PHYSICAL PROBLEMS:}

Thrombosed vein and skin infection at the injection sites were the most common findings in intravenous drug users. Two clients had hepatitis; one of them positive for hepatitis B antigen. Blood test for HIV was done in 5 intravenous drug users who shared needles but none of them was positive. In other 5 clients who shared needles, test of HIV could not be done because they were not willing to have this test.

\section{TREATMENT AND FOLLOW-UP:}

All the patients were either brought by family members or came by themselves. Only 4 clients agreed for admission and home detoxification was tried for the rest.

Table 9

\begin{tabular}{cc|cc|c} 
No & one & two & three & 4 or more \\
follow up & follow up & follow ups & follow ups & follow ups \\
32 & 12 & 7 & 2 & 2
\end{tabular}

As seen in the table 9, follow up was poor. Counseling was provided to the clients and the 
accompanying family members. Thioridazine, Benzodiazepines and NSAID were used for detoxification. Patients expected medicines which could relieve their craving and, gave them good sleep without any withdrawal symptoms. Patients who came for follow-up were abstinent of the primary drug of abuse. As most of the patients were lost after first or second follow up, outcome of treatment was poor. Only two clients stopped drug use after treatment.

Some of the reasons of taking drugs as reported by the clients:

- Friend's influence, poor relation with parents at home, and frustration in studies.

- Unhappy marital life, lack of affection from spouse and lack of interest in day to day life.

- As an alternative to alcohol use. This was particularly true for village people who were drinking alcohol regularly and were not able to give it up so chose to smoke cannabis in place of alcohol.

\section{DISCUSSION:}

Drug users were all males, of younger age groups and mainly from urban area. All of them were willing to stop drugs it they did not suffer from withdrawal symptoms and get good sleep at night.

Buprenorphine, an opioid mixed agonist-antagonist, is a potent analgesic. It has been tried for the treatment of opioid dependence but has dependence potential itself. Sublingual buprenorphine has been used as an alternative to methadone for the maintenance treatment of heroin dependence in the west, this policy is debatable in the sense that both methadone and buprenorphine also lead to dependence. "The abuse liability of buprenorphine is similar to morphine i.e. moderate rather than low" Bedi N.S. et. al. 1998. ${ }^{1}$ In this study buprenorphine intravenous was seen as the major problem. Oral buprenorphine was not abused. Sublingual buprenorphine is used in some drug treatment centres in India and Nepal for the detoxification treatment of heroin or intravenous buprenorphine.

More than $50 \%$ of drug users started drug use before the age of 20. Kandel \& Logan found that the period of major risk for initiation into cigarettes, alcohol and marijuana was completed by age 20 and for other illicit drugs (except cocaine) by age 21 , those who had not experimented with any of these substances by that age were unlikely to do so there after (Kandel \& Logan 1984). ${ }^{2}$ This is important for intervention, special attention is required in the school and initial years in the college. As the family and social environment influences the youth to abuse drugs, the role of parents is important for preventive action. Providing realistic information about the risks \& consequences of drug abuse to the target group would be useful for any preventive action.

Drug users may be taking drugs to relieve their anxiety and depression or to make them feel better. Anxiety disorders, especially social and simple phobias, appear to have an early onset in adolescence with potentially severe consequences, predisposing those affected to greater vulnerability to major depression and addictive disorders (D. A. Rogier et. al. 1998). ${ }^{3}$ Management of associated disorders may help them to stop drug use.

The global trend among those dependent on drugs is towards the use of multiple psychoactive substances, with people moving from one substance to another, and using drugs in various combinations (The World Health Report 1997). ${ }^{4}$ In the current study also, multiple psychoactive substance use was the most common.

It is estimated that 40,000 people are using drugs, and the figure for Pokhara is also likely to be high. However, drug related consultation in 20 months 
was very low. It is possible that many of the clients do not come for consultation. Educating the potential users in the risk associated with drug abuse is important for primary prevention. Detoxification, counseling and rehabilitative services for those already abusing drugs is necessary for secondary prevention and to reduce the drug abuse problem, drug related crimes and human suffering.

\section{REFERENCES:}

1. Bedi NS, Ray R, Jain R, Dhar NK: Indian J Physiol Pharmacol 1998; 42(1): 95-100.

2. Kandel D, Logan J, Patterns of drug use from adolescence to young adulthood: I. Period of risk for initiation, continued use and discontinuation. Am J Public Health 1984: 4: 660-666.

3. D. A. Rogier, D. S. Rae, W. E. Narrow, C. T. Kaelber and A. F. Schatzberg: Prevalence of anxiety disorders and their comorbidity with mood and addictive disorders. British Journal of Psychiatry (1998), 173 (suppl. 34), 24 - 28.

4. The World Health Report 1997, Conquering suffering Enriching humanity, World Health Organization Geneva: 61.

\section{$\bullet \bullet \bullet \bullet \bullet \bullet \bullet \bullet \bullet \bullet \bullet \bullet \bullet \bullet \bullet \bullet \bullet \bullet \bullet \bullet \bullet \bullet \bullet \bullet \bullet \bullet \bullet \bullet \bullet \bullet \bullet \bullet \bullet \bullet \bullet \bullet \bullet \bullet \bullet \bullet \bullet \bullet \bullet \bullet \bullet \bullet \bullet \bullet \bullet \bullet \bullet$ \\ 3rd. National Conference $O F$ \\ Society of Surgeons of Nepal 2001 , November $23^{\text {rd }}-24^{\text {th }}$ \\ Venue : Nepalgunj, Nepal.

\author{
Secretariat:
} \\ $\mathcal{N} \cdot \mathcal{M} . \mathcal{A}$. Building \\ Bheri Branch, Hospital Road,

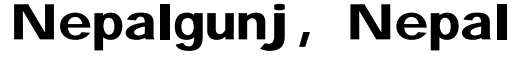 \\ Pf. $\mathcal{N o . : 0 0 9 7 7 - 8 1 - 2 2 1 3 6 , 2 2 6 6 1}$ \\ Fax: $00977-81-20305$}

